\title{
Psicoanálisis existencial y reflexión purificante en la ontología fenomenológica de Jean-Paul Sartre
}

\author{
Danila Suárez Tomé \\ Universidad de Buenos Aires/CONICET/CEF-ANCBA
}

Resumen: El artículo presenta una reconstrucción del método del psicoanálisis existencial sartriano especificando su finalidad, campo de aplicación, y provee un análisis interpretativo de su necesidad dentro del desarrollo de la ontología sartriana. Se defenderá que la meta del psicoanálisis existencial es el acaecimiento de la reflexión pura, la cual abre la posibilidad del reconocimiento del proyecto fundamental y la conversión existencial. El análisis se basa en una lectura de $E l$ ser y la nada que toma como concepto central a la noción de "deseo".

Palabras clave: psicoanálisis; fenomenología; existencialismo; reflexividad; reconocimiento

\begin{abstract}
Existential Psychoanalysis and Purifying Reflection in the Phenomenological Ontology of Jean-Paul Sartre". The article presents a reconstruction of the Sartrean existential psychoanalytic method by specifying its objective and field of application, and it provides an interpretive analysis of how it is needed in the development of Sartrean ontology. It will be argued that the goal of existential psychoanalysis is the occurrence of pure reflection, which opens up the possibility of recognition of the fundamental project and the existential conversion. The analysis is based on an interpretation of Being and Nothingness, which takes as a central concept the notion of "desire".
\end{abstract}

Keywords: psychoanalysis; phenomenology; existentialism; reflexivity; recognition 


\section{Introducción}

La ontología fenomenológica desarrollada por Jean-Paul Sartre en El ser y la nada encuentra su culminación en el establecimiento de las directrices para el desarrollo del psicoanálisis existencial. En el presente trabajo ofrezco una reconstrucción del método distintivo del psicoanálisis existencial esbozado por Sartre, así como de su finalidad, su campo de aplicación y un análisis interpretativo que busca dar cuenta de por qué la ontología fenomenológica que desarrolla debe culminar en las directrices de una propuesta psicoanalítica. La hipótesis que busco probar es que la meta del psicoanálisis existencial debe ser el acaecimiento de la reflexión pura, la cual constituye el acontecimiento que funda la posibilidad del reconocimiento del proyecto fundamental del existente humano y la conversión existencial. Considero que, si nos atenemos a esta hipótesis, se resolverian satisfactoriamente dos interrogantes que persisten en la obra sartriana: la necesidad del psicoanálisis existencial dentro del desarrollo de la ontología fenomenológica y el contexto del surgimiento de la reflexión purificante. En vías a contrastar mi hipótesis de lectura, baso mi análisis de la relación entre la ontología fenomenológica con el psicoanálisis existencial y el carácter mediador de la reflexión purificante en una clave de acceso hermenéutica a $E l$ ser y la nada que hace foco en la noción plurivoca de "deseo".

\section{Explicitación de las nociones de "falta" y "deseo" dentro de la ontología} fenomenológica sartriana

Para poder comprender cabalmente tanto la necesidad como la posibilidad del desarrollo del psicoanálisis existencial, resulta imperioso partir de un análisis del deseo tal y como se encuentra tematizado, en toda su riqueza y complejidad teórica, dentro del despliegue de la ontología sartriana. No resultaría exagerado proponer un acceso hermenéutico a $E l$ ser y la nada que tome como hilo conductor a la noción de "deseo". Si anclamos nuestra mirada teórica en la perspectiva del para-sí deseante, es posible ver cómo a través de la obra se constituye y determina cada vez con mayor precisión el concepto de "deseo" en su estructura, función y relación intrínseca con la noción de "existencia". Más aun, no resultaría demasiado osada la interpretación de nociones centrales como las de "intencionalidad", "trascendencia" y "nihilización" como 
diferentes maneras de nombrar el deseo. Para poder argumentar esta interpretación, es necesario partir de una perspectiva hermenéutica que tome como epicentro a la definición del existente humano como deseo de ser. Intentaré, en este primer apartado, exponer dicha caracterización del ser-en-el-mundo y trataré de mostrar cómo todas las notas fundamentales del ser de la conciencia (intencionalidad, trascendencia, nihilización) se reúnen en la noción de "deseo".

En la sección dedicada al psicoanálisis existencial, hacia el final de $E l$ ser y la nada, Sartre sostiene que, si algo es el existente humano, es deseo de ser puesto que el para-sí no es sino nada de ser ${ }^{1}$. Esta formulación del existente humano como deseo de ser contiene in nuce toda la descripción que Sartre había realizado del para-sí en las secciones anteriores. Esta tesis se puede constatar tanto desde una perspectiva gnoseológica, es decir, desde el análisis fenomenológico de la conciencia entendida como intencionalidad y nihilización, como desde una perspectiva ontológica, es decir, desde el análisis fenomenológico de la noción del para-sí como presencia-a-sí, trascendencia y, eminentemente, falta.

Al hablar de "deseo de ser", Sartre nos remite, en un intento de diferenciación con respecto a la multiplicidad de deseos empíricos, a un tipo de deseo que denomina "existencial", el cual hace evidente la falta de ser constitutiva del para-sí humano. En la sección consagrada a las estructuras inmediatas del para-sí, Sartre dedica una extensa parte de su análisis a describir estructuralmente dicha falta. El punto de partida del análisis radica en la vinculación que Sartre establece entre las nociones de "nihilización" y "trascendencia". La nihilización del ser constituye la vinculación originaria entre las regiones del ser, es decir, entre el para-sí, fundamento ontológico de la conciencia nihilizadora, y el en-sí. El en-sí se hace presente en la conciencia como aquello que ella misma niega ser. Al determinarse a no ser el en-sí, la conciencia se determina a sí misma como nada de ser. Sartre sostiene que dicha presencia del en-sí en la conciencia testimonia la trascendencia del para-sí: la nihilización del ser, como acto originario de la conciencia, constituye el origen de la trascendencia en tanto vínculo primario entre el ser del para-sí y el ser del en-sí2.

\footnotetext{
1 Esta conclusión, tal como la sostiene Sartre, resulta de su descripción a priori del ser del parasí: "El hombre es fundamentalmente deseo de ser, y la existencia de este deseo no tiene que ser establecida por inducción empírica: resulta de una descripción a priori del ser del para-sí, puesto que el deseo es falta y el para-si es el ser que es para sí mismo su propia falta" (Sartre, J-P., El ser y la nada, Valmar, J. (trad.), Buenos Aires: Losada, 2005, pp. 762-763).

2 Cf. ibid., pp. 250-258.
} 
Me detendré ahora en la descripción estructural de la falta. De acuerdo con Sartre, la "falta de..." es, de todas las negaciones internas del para-sí, aquella que penetra más profundamente en el en-sí. La estrategia de Sartre consiste en probar que la falta surge en el mundo solo por obra y gracia del existente humano, en tanto él es esencialmente falta. A partir de esto demuestra que, a causa de la falta estructural del para-si, su ser es necesariamente el de la trascendencia y su relación originaria con el en-sí es una relación de nihilización. Dicha demostración partirá de una descripción de la estructura de la falta, en la que se encuentran presentes tres componentes esenciales: 1o faltante, lo "falto de..." y lo fallido. Lo que expresa la falta, es decir, lo que se da a la intuición, es un ser incompleto: lo faltante. Dicha noción, la de "ser incompleto", se presenta, en su esencia, como una contradictio in adjecto, dado que al en-sí, justamente por ser pleno y saturado ${ }^{3}$, no le falta nada. Por ende, para que lo faltante pueda constituirse como tal, es necesario que sea puesto por un existente que trascienda el ser hacia lo fallido. Así, lo faltante se encuentra determinado por la totalidad sintética de lo fallido. En otras palabras, lo faltante, para constituirse en "ser incompleto", se encuentra determinado por lo que no es, es decir, por la totalidad sintética de lo fallido. Exploremos el ejemplo que da Sartre para iluminar lo anterior: “...si digo que la luna no está llena y que le falta un cuarto, formulo este juicio sobre una intuición plena de un cuarto creciente o menguante. Así, lo que se da a la intuición es un en-sí, que, en sí mismo no es ni completo ni incompleto, sino que es simplemente lo que es, sin relación con otros seres. Para que este en-sí sea captado como cuarto de luna, es menester que una realidad humana trascienda lo dado hacia el proyecto de la totalidad realizada - en este caso, el disco de la luna llena- y vuelva luego hacia lo dado para constituirlo como cuarto de luna; es decir, para realizarlo en su ser a partir de la totalidad, que se convierte en fundamento de él"4.

En el ejemplo expuesto podemos constatar la arquitectura trinitaria de la falta: la luna en cuarto creciente o menguante es el existente "falto de...";

1503 Sartre sostiene, en la Introducción a El ser y la nada, que "el ser es. El ser es en sí. El ser es lo que es" (ibid., p. 38). Estas tres características son las tres notas distintivas del ser-en-sí, y no del ser en general, en tanto el ser en general comprende tanto al ser-para-sí como al seren-sí. Podemos entender de modo más claro estas tres notas distintivas si las traducimos en las siguientes características: a) Identidad: el ser es en sí porque no remite a sí como lo hace la conciencia (de) sí. El ser mismo es ese sí. Es identidad; b) Opacidad: el ser en sí está lleno de sí mismo. Es pleno. Es macizo; c) Contingencia: el ser no puede ser ni derivado de lo posible (lo posible es una estructura del para-sí) ni reducido a lo necesario (la necesidad concierne a la conexión de proposiciones ideales y no a la de los existentes). Es contingente, sin razón de ser.

4 Ibid., p. 145. 
el cuarto de luna, lo faltante, y el disco de la luna llena, lo fallido. El punto de Sartre es que para que se pueda constituir lo faltante, el "falto de..." debe ser trascendido hacia lo fallido por un existente que sea en sí mismo su propia falta. Y ello debe ser así porque la falta no puede emerger del ser, dado que él mismo es pura positividad $-\mathrm{y}$, como reza el ejemplo citado, la intuición plena del cuarto creciente es un en-sí que es simplemente lo que es-, sino que debe surgir de la propia nada. Por ende, la falta adviene al mundo por un ser que es en sí mismo falta. Teniendo en cuenta las descripciones que habia realizado previamente del para-sí, resulta forzoso sostener que la falta adviene al mundo por el existente humano quien es, en sí mismo, carente de ser. Esto último es precisamente lo que reza la famosa frase de El existencialismo es un humanismo, según la cual en el ser humano la existencia precede a la esencia.

Inmediatamente, Sartre sostiene que la existencia del deseo es una prueba de que la realidad humana es constitutivamente falta. Esta afirmación supone una concepción tanto negativa como existencial del deseo: negativa, en tanto el deseo es entendido aquí como expresión de carencia; existencial, porque la existencia del deseo refiere a la propia constitución ontológica del existente humano y no a un estado psíquico que él posee. Un estado psíquico para Sartre, ya desde La trascendencia del ego y el Esbozo de una teoria de las emociones, es un ser-en-sí, un objeto trascendente a la conciencia que se constituye, a través de la actividad reflexiva, como polo de unidad de actos intencionales prerreflexivos. Por ende, el deseo empírico, el deseo qua estado psíquico, sería pura positividad y no precisaría de nada para completarse. Dentro de estos términos, podemos sostener que la idea de un deseo entendido como estado psíquico es un concepto contradictorio. En palabras de Sartre: "Guardémonos, pues, de considerar los deseos como pequeñas entidades psíquicas que habiten la conciencia: son la conciencia misma en su estructura original pro-yectiva y trascendente, en tanto que es por principio conciencia de algo"5.

Una vez aceptado esto, que el deseo sea un indicio de la falta constituyente del existente humano nos sugiere dos cosas. Primero, que la falta no se manifiesta en sí misma, es decir, que es transfenoménica. Segundo, que nuestra manera de apercibirnos de la falta que nos constituye ontológicamente es a través de la experiencia de nuestro deseo. Dicho de otra manera, la forma en la que la falta se manifiesta a sí misma, puesto que el para-sí es falta, es como deseo. Concentrémonos en la primera tesis según la cual la falta es transfeno-

\footnotetext{
5 Ibid., p. 752.
} 
ménica. De acuerdo a los lineamientos expresados en la introducción a $\mathrm{El}$ ser y la nada, para poder emprender una investigación ontológica hay que trazar una distinción entre el fenómeno de ser y el ser del fenómeno, es decir, entre la manifestación del ser en el campo del conocimiento -aquella que aprehende y describe la ontología fenomenológica- y el ser transfenoménico, que es la condición ontológica y coextensiva a esta develación. Escribe Sartre: “... el fenómeno de ser exige la transfenomenalidad del ser... el ser del fenómeno, aunque coextensivo al fenómeno, debe escapar a la condición fenoménica -que consiste en no existir algo sino en cuanto se revela-; y que, en consecuencia, desborda y funda el conocimiento que de él se tiene". Se comprende, entonces, que si el para-sí es el ser transfenoménico de la conciencia y el para-sí es constitutivamente falta -más específicamente, falta de ser-, la falta, entonces, es en sí misma transfenoménica.

Vayamos ahora a la segunda tesis: que la falta se manifiesta a sí misma bajo la forma del deseo. Para poder sostener argumentativamente dicha tesis debo primero especificar la noción de "deseo". Dicha noción presenta, al igual que la de "falta", una arquitectura trinitaria, aunque no en sus elementos constitutivos, sino en sus niveles de manifestación. ¿Cómo comprende Sartre el deseo? Antes que nada, como trascendencia: "un escapar de sí hacia un objeto deseado" . Este deseo entendido como tendiente a un objeto particular responde a la tercera noción de deseo que podemos rastrear en la ontología sartriana: el "deseo empírico". Sin embargo, debemos tener en cuenta que la multiplicidad de deseos particulares fácticos a través de los cuales nos situamos en el mundo son la manifestación de un deseo que no es empírico, es decir, que no es óntico, sino ontológico. Existe un tipo de deseo más originario y es el "deseo generalizado de ser", al cual también denomina Sartre la "elección originaria" y que no resulta fenomenológicamente accesible de manera directa, sino que se manifiesta a través de la multiplicidad de deseos particulares. Ahora bien, entre ambas nociones de deseo se encuentra un eslabón fundamental para que el deseo generalizado de ser devenga en una multiplicidad de deseos empíricos, que es el deseo como "elección fundamental" o "proyecto". Dicha elección, a diferencia de la originaria, constituye el modo específico en el cual el existente humano elige vivir. En palabras simples, la elección fundamental o proyecto fundamental constituye lo que llamamos la "persona" en tanto núcleo esencial del existente humano que expresa a la vez el deseo generalizado de ser y dota

${ }^{6}$ Ibid., p. 17.

7 Ibid., p. 147.

ARETÉ Revista de Filosofía, vol. XXIX, N 1, 2017 / ISSN 1016-913X 
de significación a la pluralidad de los deseos empíricos. Para especificar esta tipología, cito la síntesis presentada por Judith Butler en Sujetos del deseo: "La primera de estas elecciones, el deseo original de ser, no tiene estatus ontológico independiente, sino que se expresa, principalmente, por medio de la elección fundamental: 'el deseo de ser se realiza siempre como el deseo de un modo de ser'. Y ni la elección originaria ni la elección fundamental se hacen conocer de manera directa en la experiencia, sino que tienen que aparecer en la 'infinidad de deseos concretos que constituyen la trama de nuestra vida consciente'. Por esta razón, los deseos particulares expresan al mismo tiempo la especificidad del yo, la decisión radical acerca de cómo ser que distingue a los individuos entre sí, y los proyectos anónimos y universales del yo 'de ser', es decir, de superar la disyunción ontológica de la conciencia y su mundo"8.

Habiendo hecho esta conceptualización de la noción de deseo, me encuentro ahora en condiciones de argumentar por qué el deseo es la manifestación de la falta. ¿Qué significa que la realidad humana es originariamente deseo de ser? Que ella busca, a través de su mero existir, ser idéntica consigo misma, superar la escisión entre el para-sí y el en-sí y totalizarse en un en-sí-para-sí, esto es, en un en-sí que fuera su propio fundamento. Este en-sí-para-sí, también expresado como el proyecto de ser Dios, constituye el valor del proyecto del para-sí. Esto significa que el en-sí-para-sí es lo fallido. ¿Qué es lo que le falta al para-sí? El sí mismo como en-sí, es decir, la identidad. El sentido del deseo de ser, de la tendencia a la existencia del para-sí, se define por un en-sí fallido que es pura ausencia. Esto lleva a Sartre a sostener la famosa frase que reza que el hombre no es más que una pasión inútil, puesto que el proyecto de ser del para-sí es ontológicamente imposible, esto es, un fracaso ${ }^{9}$.

Con la noción sartriana de "deseo" ya completamente delimitada, intentaré explicar ahora por qué considero que dicha noción es plurivoca. De acuerdo con la hipótesis que establecí al comienzo del presente apartado, he buscado sostener una lectura de la ontologia sartriana centrada en la noción de "deseo" como el revés ontológico de las nociones gnoseológicas de "nihilización", "intencionalidad" y "trascendencia". La operación no resulta demasiado dificultosa: en tanto y en cuanto el para-sí, como fundamento ontológico del cogito prerreflexivo, es definido como falta, es decir, como deseo de ser, se comprende cómo puede ser definido como trascendente al mismo tiempo. El

\footnotetext{
8 Butler, J., Sujetos del deseo. Reflexiones hegelianas en la Francia del siglo XX, Luján, E. (trad.), Buenos Aires: Amorrortu, 2012, p. 183.

9 Cf. Sartre, J-P., El ser y la nada, p. 828.
} 
para-sí es en tanto se trasciende hacia aquello que no es, el en-sí, negando serlo, es decir, nihilizándolo. Esta operación es traducida en términos cogitativos como intencionalidad. Sartre reformula ya la noción de intencionalidad en su texto Una idea fundamental de la fenomenologia de Husserl: la intencionalidad, entendiéndola plenamente como trascendencia y nihilización, como un "excederse a sí misma", negando ser lo otro de sí. Y el fracaso ontológico se encuentra ya tematizado en dicho artículo cuando Sartre sentencia que "si la conciencia trata de recuperarse, de coincidir al fin con ella misma, en caliente, con las ventanas cerradas, se aniquila"10.

\section{De la ontología fenomenológica al psicoanálisis existencial}

Según he establecido anteriormente, el deseo ostenta una estructura trinitaria. En un primer nivel, tenemos el deseo generalizado de ser, el cual siempre se expresa como deseo de ser de tal o cual manera frente a sí mismo, los otros y el mundo. Ello es lo que Sartre denomina "elección fundamental", "proyecto fundamental" o, simplemente, "persona". Sin embargo, quedó establecido que dicho proyecto fundamental no es conocido sino a través de los múltiples deseos concretos y conductas del existente humano. Esto nos indica, sin más, que el existente humano, lejos de ser transparente para sí mismo, tiene que lidiar indefectiblemente con la opacidad. A la base de esta idea se encuentra una concepción compleja de la subjetividad. Ya desde La trascendencia del Ego, y todavía más en El ser y la nada, Sartre opera con una concepción no egológica de la subjetividad. Esto se traduce en un par de oposiciones que, según entiendo, se sostienen a lo largo de la ontología sartriana con claridad meridiana: conciencia no es equivalente a ego, subjetividad no es sinónimo de personalidad. Que la subjetividad no sea egológica permite a Sartre sostener la imposibilidad ontológica de la identidad del sujeto consigo mismo. Originariamente, el sujeto es diferencia, imposibilidad de coincidencia consigo mismo, el para-sí es "presencia a sí..." y se encuentra escindido por un abismo que le permite ser portador de dicha estructura. Estas conclusiones son las que se desprenden 154 de la descripción fenomenológica llevada a cabo en su investigación ontológica. La descripción revela la verdad del cogito prerreflexivo, su primacía ontológica con respecto al cogito reflexivo, la artificialidad y condición derivada de la esfera egológica y la ineludible estructura del ser-para-otro como condición de la

10 Sartre, J-P., "Una idea fundamental de la fenomenología de Husserl: la intencionalidad" en: Situaciones I, Buenos Aires: Losada, 1967, p. 26. 
constitución de la personalidad del existente humano. Intentaremos ver ahora cómo se produce el paso de las conclusiones de la descripción ontológica hacia la necesidad del desarrollo de un psicoanálisis existencial.

En Para una moral de la ambigüedad, Simone de Beauvoir sostiene categóricamente que, sin el fracaso constitutivo de la existencia humana, no existiría necesidad de una moral. La ontología existencialista sostiene que ese fracaso es definitivo, no suprimible: “... en su vana tentativa por ser Dios, el hombre se hace existir como hombre, se satisface con esta existencia, coincide exactamente consigo mismo. No le está permitido existir sin ternura hacia ese ser que no será nunca; pero le es imposible querer esa tensión con el fracaso que la misma implica. Su ser es carencia de ser, pero hay una manera de ser de esta carencia que es, precisamente, la existencia... Para alcanzar su verdad, el hombre no debe procurar disipar la ambigüedad de su ser, sino por el contrario, aceptar realizarla: solo vuelve a encontrarse en la medida en que consiente permanecer a distancia de sí mismo"11. Aceptar la existencia como un fracaso es la conditio sine qua non de la conversión existencialista, del paso a una existencia auténtica que escape a la mala fe. El psicoanálisis existencial puede ser visto como una de las vias para lograr dicha conversión a través del acaecimiento de la reflexión purificante.

Sartre define al psicoanálisis existencial como un "método destinado a sacar a la luz, con una forma rigurosamente objetiva, la elección subjetiva por la cual cada persona se hace persona, es decir, se hace anunciar lo que ella misma es"12. Su ámbito de aplicación es la persona, es decir, trabaja sobre la elección fundamental o proyecto fundamental que vimos como segundo nivel en la estructura tripartita del deseo, y su método se compone por un intento de reducción de los comportamientos singulares a las relaciones de ser que se expresan en los mismos ${ }^{13}$. El psicoanálisis existencial tiene su posibilidad como método allí donde la investigación ontológica llega a su fin. Francis Jeanson,

11 De Beauvoir, S., Para una moral de la ambigüedad, Solero, F.J. (trad.), Buenos Aires: Schapire, 1956, pp. 14-15.

12 Sartre, J-P., El ser y la nada, p. 775.

13 A propósito de esta expresividad del proyecto en los comportamientos singulares, aprovecho para hacer una breve mención a la relación positiva del psicoanálisis existencial con el psicoanálisis freudiano. En su libro Conscience, ego et psyché, Jean-Marc Mouillie sintetiza aquello que Sartre retoma del psicoanálisis freudiano, aun luego de su dura crítica a la noción de inconsciente, del siguiente modo: "Sartre elogia al psicoanálisis el haber rechazado un 'determinismo psíquico horizontal', la interpretación de un acto por lo precedente, y reconocido la expresividad simbólica de nuestros actos. Este punto de acuerdo justifica su inclusión del término 'psicoanálisis' en la expresión 'psicoanálisis existencial', la cual da nombre a la 'metodología fenomenológica especial' encargada de explicitar el proyecto fundamental que es mi ser. El acto reenvía a 
en su obra dedicada a una interpretación ética de $E l$ ser y la nada titulada $E l$ problema moral y el pensamiento de Sartre, sintetiza la diferenciación entre la ontología y el psicoanálisis de la siguiente manera: "En cuanto estructura abstracta de la existencia humana, la libertad es accesible a una fenomenología ontológica; en el otro extremo, la nomenclatura de los deseos empíricos debe convertirse en el objeto de investigaciones propiamente psicológicas; pero entre estos dos dominios se ubica el de los deseos fundamentales según los cuales la libertad manifiesta existencialmente su estructura abstracta; en este nivel se encuentra la persona, y tal es el terreno de investigación del psicoanálisis existencial"14. En tanto la persona es una totalidad, no basta con recomponerla a través de la suma de sus comportamientos empíricos. Esto es, según Sartre, lo que la psicología clásica intentó hacer. El psicoanálisis existencial, por el contrario, trabaja con dichas conductas para reconducirlas a una significación trascendente. Toda actitud empírica es la expresión significativa de la elección de un carácter inteligible. No obstante, ese hiato entre la actitud empírica y la elección fundamental, definido mediante una relación de significación, no es un verdadero hiato en tanto se trata del mismo fenómeno. Esto es, las actitudes empíricas, las conductas particulares del existente humano y sus deseos concretos, son la manera en que la elección fundamental, como elección de manera de ser, se manifiesta. Son el reverso fenoménico del deseo existencial transfenoménico, el cual no resulta, entonces, ni temporal ni ontológicamente primario, sino coextensivo con su manifestación empírica.

En conclusión, lo que el psicoanálisis existencial busca es extraer la significación fundamental del proyecto originario de cada existente humano. A diferencia de la ontología, el psicoanálisis existencial es un método de indagación individual, de autoconocimiento, que busca el proyecto fundamental común a las diversas tendencias empíricas de un individuo, las cuales se encuentran en una relación de expresión y satisfacción simbólica con dicho proyecto. El punto de partida metodológico es la experiencia del individuo y su punto de apoyo radica en la comprensión pre-ontológica que él mismo tiene de sí. Dicha comprensión refiere al proyecto de devenir Dios como valor supremo de la existencia; es decir, el proyecto fallido que dota de significación a los posibles hacia los cuales el para-sí libre se trasciende en busca de completarse a

estructuras que no son inmediatamente inteligibles y que él traduce simbólicamente" (Mouillie, J-M., Conscience, ego et psyché, París: PUF, 2000).

${ }_{14}$ Jeanson, F., El problema moral y el pensamiento de Sartre, Llanos, A. (trad.), Buenos Aires: Siglo Veinte, 1968, p. 256. 
sí mismo a causa de su carencia ontológica. Pero lo que el existente humano busca a través del psicoanálisis existencial es arrojar luz sobre aquello que originariamente ya comprende pero se le aparece como opaco. En el próximo y último apartado, trabajaremos sobre la posibilidad de acceso cognoscitivo al proyecto fundamental.

\section{El espacio estratégico de la reflexión purificante dentro del psicoanálisis existencial}

Me preguntaré ahora si acaso la reflexión purificante podría ser considerada la meta del psicoanálisis existencial. Ya he explicitado que el psicoanálisis existencial busca desvelar la elección fundamental del individuo, es decir, la manera en la cual se especifica su deseo generalizado de ser. En la primera parte de mi trabajo, me propuse argumentar cómo es posible traducir los conceptos gnoseológicos de "intencionalidad", "nihilización” y "trascendencia" como distintas maneras de nombrar el deseo. El movimiento del para-sí al en-sí es un movimiento desiderativo. Vincent de Coorebyter sostiene que la intencionalidad en la ontología sartriana, entendida como deseo, no expresa una apertura serena a una plenitud de ser sino una búsqueda desesperada de dicha plenitud ${ }^{15}$. Pero, ¿ qué pasa cuando el para-sí se repliega sobre sí mismo, es decir, cuando tiende no hacia el ser sino hacia la nada? El movimiento reflexivo del para-sí es una de las temáticas más importantes de la ontología sartriana que nos abre a una serie de enigmas aún no resueltos en torno a la noción de "reflexión" y su desdoblamiento en "reflexión cómplice" y "reflexión pura".

Sartre sostiene, tanto en La trascendencia del ego como en El ser y la nada, la existencia de dos tipos distintos de actos reflexivos: puros y cómplices. Mientras que los últimos proveen conocimiento de vivencias objetivadas, los primeros ofrecerían la posibilidad de un acceso no-tético a las vivencias, pero solo a costa de que la reflexión no fuese motivada, es decir, que no fuese voluntaria. De ser motivado, el acto reflexivo no será puro y únicamente podrá dirigirse sobre el cogito reflexivo, mas no sobre el prerreflexivo, que es el nivel de acceso que tendria la reflexión pura. La reflexión pura consistiria en la constatación de la simple presencia del para-sí a sí mismo. El drama de la reflexión, según Sartre, redunda en que como todo acto de la conciencia es tendencia hacia el ser, cuando ella misma intenta captar su propia nada constitutiva, no

15 Cf. De Coorebyter, V., "Les paradoxes du désir dans L'Être et le Néant" en : Barbaras, R. (ed.), Sartre: Desir et Liberté, Paris: PUF, 2005. 
logra aprehenderla, sino que se encuentra irremediablemente con su sustancialización: el ego. Sin embargo, dice Sartre, la reflexión pura, como aquella posibilidad de asir a la conciencia en su vacuidad, en su fluir puro, resta como un acaecimiento siempre posible en la vida del existente humano.

El problema que nos trae la noción de reflexión pura es que Sartre sostiene, tanto en La trascendencia del ego como en El ser y la nada, que es poco probable que pueda ser efectuada, a pesar de ser por derecho posible, pues la condición fundamental de su existencia es la falta de motivación. Por ello, pareciera que la reflexión pura debe acaecer sin ningún sujeto que sea su ejecutor. Entonces, ¿'es de hecho la reflexión pura una reflexión? Repasaré, primero, su conceptualización en la obra de Sartre y luego presentaré una interpretación propia para poder finalmente delimitar de modo más claro su función mediadora entre la ontología y el psicoanálisis existencial.

La reflexividad se encuentra tematizada como un fenómeno complejo que puede ser analizado en tres niveles diferenciados: la prerreflexividad, la reflexividad pura y la reflexividad cómplice. Lo que se presenta en cada nivel es un tipo de relación de la conciencia consigo misma que se distingue de los otros por ser más o menos posicional, es decir, objetivante. Las raíces de la reflexividad encuentran su origen en la constitución temporal de para-sí. Mostraré, antes que nada, cómo es que la temporalidad se relaciona con la reflexividad en sus formas pura y cómplice. Si bien Sartre presenta una teoría sistemática de la temporalidad en lo que respecta a los éxtasis temporales, existe una especificación en torno a la misma que resulta ontológicamente más originaria: la diferenciación entre la temporalidad original y la temporalidad psíquica. Sartre define a la primera como "duración del para-sí como conciencia no-tética (de) durar"16, con lo que queda asentado inmediatamente que la temporalidad original es la vivencia prerreflexiva que de la temporalidad tiene el para-sí. En términos más sencillos, es la existencia temporal del para-sí. Por otro lado, la segunda temporalidad, la psíquica, es definida como una "conciencia tética de la duración: captación de sí mismo como unidad de sucesión”"17. La temporalidad psíquica, por ser conciencia posicional de la duración, encuentra su fundamento ontológico en la temporalidad originaria. La diferencia entre ambos tipos de conciencias de la duración del para sí es, dicho de manera prosaica, que en el primer caso el para-sí existe en su duración mientras que, en el segundo caso, el

${ }^{16}$ Sartre, J-P., El ser y la nada, p. 221.

${ }^{17}$ Ibid., pp. 221-222. 
para-sí logra captarse a sí mismo como una unidad temporal, como un "objeto" que se da en el tiempo. Como la conciencia de ser una unidad temporal es una conciencia de una conciencia (de) ${ }^{18}$ duración, Sartre advierte con acierto que el meollo de la problemática de la temporalidad del para-sí debe ser esclarecido a partir de la explicitación fenomenológica del mecanismo reflexivo. Y dicha ligazón esencial entre temporalidad y reflexión no solo va a esclarecer este carácter bifronte de la temporalidad del para-sí sino que, además, permitirá a Sartre concebir una noción de reflexión que no se agote en la instantaneidad de la evidencia apodíctica cartesiana del cogito.

¿En qué consiste la reflexión en su definición más simple? La reflexión no es más que el para sí tomando conciencia posicional de sí mismo. Pero en tanto el para-sí ya era conciencia (de) sí mismo, esto es, conciencia no posicional de sí mismo ${ }^{19}$, la reflexión, más puntillosamente, se define como la conciencia de la conciencia (de) sí. Esto instituye dos niveles intraconcienciales: (1) una conciencia (de) sí que (2) se toma a sí misma como objeto de reflexión. La operación de reflexión es ella misma irreflexiva, si no lo fuera, se correría el riesgo de una regresión al infinito. Por lo tanto, y precisando todavía más nuestra definición, la operación de la reflexión consiste en una conciencia irreflexiva que toma como objeto de reflexión a un reflejo ${ }^{20}$ constituido por la dualidad reflejo-reflejante del para-si en su origen prerreflexivo. Pero como ha quedado establecido previamente, la reflexión es un fenómeno complejo que presenta varios niveles, por lo cual no podemos detenernos en este esquema simple. Cada nivel de la reflexividad del para-sí nos enfrenta a un tipo de relación de la conciencia consigo misma que puede ser más o menos objetivante. Un rastreo de dichas relaciones a través de $E l$ ser y la nada nos permite clasificarlas en tres categorias: la presencia-a-sí, como la instancia prerreflexiva de conciencia no posicional del para-sí, de la cual no me ocuparé en el presente trabajo por

\footnotetext{
18 El "(de)" es una marca del lenguaje escrito que utiliza Sartre para establecer que no se trata de una conciencia reflexiva sino prerrefleixva.

${ }_{19}$ Sartre demuestra, tanto en El ser y la nada como en su ensayo previo La trascendencia del ego, que el cogito cartesiano (y husserliano) es derivado de una instancia más originaria: el cogito prerreflexivo. Para Sartre la conciencia posee la siguiente estructura: en un nivel 1, la conciencia intenciona un objeto trascendente negando ser ese objeto (intencionalidad como trascendencia y nihilización), mientras que en un nivel 2 la conciencia se auto-capta prerreflexivamente en esta actividad intencional. Esta es la ley de la existencia de la conciencia: ser conciencia (de) sí como conciencia de algo o, en otros términos, ser conciencia no posicional de sí como conciencia posicional de un objeto trascendente. Esta es la estructura del cogito prerreflexivo. No hay necesidad de ningún tipo de reflexión en la existencia más originaria de la conciencia.

20 Tomamos la palabra "reflejo" de la traducción de Juan Valmar de El ser y la nada del vocablo "réfléchi" cuya definición es "lo que es objeto de reflexión".
} 
no constituir un acto reflexivo en sí mismo; el reconocimiento, como el nivel en el cual la conciencia, a través de la reflexión pura, se pone a sí misma como cuasi-objeto; y el auto-conocimiento, que constituye un acto de reflexión objetivante pleno. ¿'Se puede sostener que en alguno de estos niveles el para-sí logra aprehenderse a sí mismo tal como es? Dicha pregunta resulta complicada en tanto que el para-sí es definido por Sartre como aquel ser que es lo que no es y no es lo que es ${ }^{21}$. La ambigüedad ontológica del para-sí que se resume en su imposibilidad de identidad consigo mismo parece dejar obsoleta nuestra pregunta. De todas formas, creo encontrar una respuesta en la filosofia sartriana que satisface mi pregunta respetando la ambigüedad ontológica del para-sí. Sin embargo, antes de abordar dicha respuesta debo dejar asentada la relación intrinseca entre temporalidad y reflexión.

Ya que el para-sí se temporaliza, resulta de ello que la reflexión, como modo de ser del para-sí, debe ser como temporalización. Entonces, lo reflejo incluye necesariamente pasado y porvenir. Por naturaleza, la reflexión extiende sus derechos y su certeza hasta las posibilidades que yo soy y hasta el pasado que yo era. Lo reflexivo y lo reflejo se distinguen en la unidad de su ser común por el futuro y el pasado. En palabras de Sartre "el para-sí que se hace existir en el modo del desdoblamiento reflexivo, en tanto que para-sí, toma su sentido de sus posibilidades y de su porvenir; en este sentido, la reflexión es un fenómeno diaspórico; pero, en tanto que presencia a sí, es presencia presente a todas sus dimensiones ek-státicas" 22 . La reflexión, entonces, es conciencia de las tres dimensiones ek-státicas del para-sí. En el caso de la reflexión pura, es conciencia no tética (de) fluir. La reflexión pura revela la temporalidad en su no-sustancialidad originaria, esto es, revela la temporalidad originaria del para-sí, descubre las posibilidades en tanto que posibles, devela el presente como trascendente y, si bien el pasado se le aparece como en-sí, es sobre el fundamento de la presencia. Descubre el para-sí como "lo reflejo" por excelencia, es decir, como el ser que no es nunca sino como sí mismo y que es siempre ese "sí mismo" a distancia de sí, en el porvenir, en el pasado y en el mundo. Finalmente, capta la temporalidad en tanto que ella es el modo de ser único e incomparable de una ipseidad, es decir, como historicidad. La apodicticidad de la reflexión pura no admite dudas, en la medida en que capta el pasado exactamente como es para la conciencia refleja que tiene-de-serlo. En

21 Cf. Sartre, J-P., "La mala fe", en: El ser y la nada, Buenos Aires: Losada, 2005, pp. 43-57.

22 Sartre, J-P., El ser y la nada, p. 230. 
el caso de la reflexión cómplice, nos encontramos con una conciencia tética de duración psicológica en tanto sucesión de formas temporales organizadas. La temporalidad psiquica es derivada, no procede directamente de la temporalidad originaria. Empero, a la vez es incapaz de constituirse y precisa de la reflexión cómplice para ser constituida. La reflexión cómplice, como hemos dicho, implica la reflexión pura pero la trasciende al extender sus pretensiones, por lo que pierde sus derechos de apodicticidad. Constituye la sucesión de hechos psíquicos o psique y se da primeramente en la vida cotidiana, aunque incluye en sí la reflexión pura como su estructura original. El para-sí está condenado a ser para-sí, como descubre la reflexión pura. No obstante, la reflexión cómplice, que es el movimiento reflexivo primero según el tiempo de los relojes, mas no originario según lo que revela la ontología fenomenológica, es para-ser-lo-reflejo en el modo de un en-sí. Desde que la reflexión adopta un punto de vista sobre lo reflexivo, desde que se pone como no siendo lo reflejo y determina lo que éste es, la reflexión hace aparecer un en-sí susceptible de ser determinado, cualificado, detrás de lo reflejo. Así, el para-sí pierde su no sustancialidad originaria y se capta como un objeto. En palabras de Sartre: "El objeto trascendente que ha aparecido detrás del para-sí reflejo es el único ser de cual lo reflexivo pueda decir que él no lo es. Pero es una sombra de ser: es ser sido, y lo reflexivo tiene de serlo para no serlo. Esta sombra de ser, correlato necesario y constante de la reflexión, es lo que el psicólogo estudia con el nombre de hecho psíquico... Así, la reflexión es impura cuando se da como 'intuición del para-sí en el en-sí'; lo que se le devela no es la historicidad temporal y no sustancial de lo reflejo; es, allende este reflejo, la sustancialidad misma de formas organizadas de fluencia"23. Gracias a la reflexión cómplice, o impura, quedan constituidos los hechos psíquicos y su temporalidad. Sin embargo, es mi intención ahora volver al caso de la reflexión pura.

Había establecido con respecto a la reflexión pura que ella es aquel modo de reflexión en el cual la conciencia se toma a sí misma como "cuasi-objeto" y no como objeto. Es decir, es una reflexión que se queda literalmente "a mitad de camino". Entiendo que la necesidad conceptual de dicha reflexión se encuentra dada por el hecho de que a nivel prerreflexivo el para-sí existe sin tomar nota de sí en tanto existente. Por otro lado, en el nivel reflexivo cómplice, el para-sí logra tomar nota de sí mismo en tanto existente pero so pena de falsear su naturaleza en tanto solo puede ser aprehendido como un objeto y no como un

${ }^{23} \quad$ Ibid., p. 235. 
sujeto. Conceptualmente, entonces, la reflexión purificante vendría a comportar la posibilidad de una aprehensión no objetiva de la subjetividad del para-sí. Esto es, comportaría la evidencia apodictica de la subjetividad del para-sí que sería un aprehenderse a sí mismo tal como es. Pero, ¿es posible de hecho una reflexión pura? Para contestar dicha pregunta abordaremos, primeramente, dos características fundamentales de la reflexión: el fracaso que le da origen y su esencia posicional.

Atendiendo a la noción misma de reflexión, previamente a distinguirla como pura o impura, podemos notar que corresponde a un movimiento del para-sí que se origina en un fracaso. De acuerdo a Sartre, "la motivación de la reflexión consiste en una doble tentativa simultánea de objetivación y de interiorización. Ser para sí mismo como el objeto-en-sí en la unidad absoluta de la interiorización, he ahí lo que el ser-reflexión tiene de ser"24. Este esfuerzo por ser para si-mismo su propio fundamento, por recobrar y dominar su propia huida hacia el en-sí en interioridad resulta en el fracaso que es la reflexión. Más sucintamente, la reflexión se origina en un fracaso porque en el intento del para-sí de recuperarse a sí mismo en una totalidad interior, se encuentra con una nada que tiene-de-ser y que lo escinde. La distancia entre el reflejo y el reflexivo es una nada que ese para-sí tiene indefectiblemente de ser. Asimismo, toda reflexión, para Sartre, es un tipo de conocimiento porque es posicional: afirma a la conciencia refleja. Aun así, esta afirmación está condicionada por una negación: afirmar este objeto es negar que yo sea este objeto. Conocer es hacerse otro. Con todo, el problema en el caso reflexivo puro es que dicha afirmación queda inevitablemente a medio camino, pues su negación no puede realizarse enteramente. Esto concluye en una imposibilidad de la reflexión pura de adoptar un punto de vista sobre lo reflejo. El conocimiento que otorgaría la reflexión pura debería tener el carácter de lo totalitario. Sartre describe al reconocimiento producido por la reflexión pura como una intuición fulgurante y sin relieve. Todo es dado a la vez en una suerte de proximidad absoluta. La reflexión pura nos entregaría lo reflejo no como algo dado, sino como el ser que tenemos-de-ser. En este sentido, creemos que aquello que nos habría de revelar la reflexión purificante es el proyecto del para-sí temporal en tanto que él es falta y deseo de ser.

Según lo que he desarrollado a lo largo de este trabajo, la realidad humana es, para Sartre, originariamente deseo de ser. Esto significa que ella busca,

24 Ibid., p. 226. 
a través de su mero existir, ser idéntica consigo misma, superar la dualidad ontológica entre el para-sí y el en-sí y totalizarse en un en-sí-para-sí, esto es, en un en-sí que fuera su propio fundamento. Como he mostrado, el proyecto de ser del para-sí es ontológicamente imposible o un fracaso que se revelaría a la conciencia en su ser reflexivo puro. Así, la imposibilidad de una identidad del para-sí consigo mismo se expresa ontológicamente en la noción del para-sí como falta. Y la reflexión pura, entendemos, seria la forma en la cual el para-sí podría aprehender dicha falta.

Sentado esto, ¿en dónde se conectan la reflexión purificante y el psicoanálisis existencial? En que Sartre sostiene en ambos casos la posibilidad de acceder a la elección fundamental y transformarla. En los Cahiers pour une morale, Sartre sostiene que la reflexión pura es la condición de la conversión existencial y que a partir de la misma se debe generar una transformación en la relación del para-sí con su cuerpo, con el mundo, con el otro y consigo mismo. Esto quiere decir que el para-sí debe lograr reivindicar la contingencia, el desvelamiento del en-sí, la subjetividad como no egológica y el otro como un prójimo-sujeto. La conversión redunda en "el reconocimiento de mí mismo como para-sí ek-stático" 25 . Y dicho reconocimiento no es otra cosa que una reflexión pura, que toma a la conciencia no como objeto sino como cuasi-objeto, capaz de ser retenida en lo que tiene de subjetivo, allende la actitud de mala fe mundana. Asimismo, Sartre sostiene en El ser y la nada que, al buscar el psicoanálisis existencial la significación de las tendencias individuales en un proyecto contingente, irreductible y singular, que logre "iluminar" al sujeto para que este logre "tocar y ver" lo que él mismo es, abre la posibilidad para la revocación de dicho proyecto y su conversión en un proyecto de autentici$\operatorname{dad}^{26}$. Sin embargo, Sartre sostiene categóricamente que la reflexión purificante no sirve de base para el psicoanálisis existencial: "La reflexión capta a la vez símbolo y simbolización; está, cierto es, constituida integramente por una comprensión pre-ontológica del proyecto fundamental; mejor aun: en tanto que la reflexión es también conciencia no tética de sí como reflexión, es ese mismo proyecto, lo mismo que la conciencia no-reflexiva. Pero no se sigue de ello que disponga de los instrumentos y técnicas necesarios para aislar la elección simbolizada, aislarla en conceptos y sacarla así aislada a plena luz. La reflexión está penetrada de una gran luz, sin poder expresar lo que esta luz

25 Sartre, J-P., Cahiers pour une morale, París: Gallimard, 1983, p. 19.

${ }^{26}$ Cf. Sartre, J-P., El ser y la nada, p. 774. 
ilumina"27. Los datos de la reflexión individual deben ser acompañados por la observación objetiva del psicoanalista. Esto implica, en definitiva, que la única posibilidad de conocer aquello que el para-sí comprende preontológicamente es a partir de la mediación de un otro. Esto no sorprende, dado que ya en su tratamiento de la mirada, Sartre había probado que la única forma de poder generar un movimiento reflexivo dentro del para-sí era a causa del saberse mirado por un prójimo ${ }^{28}$. De ello se sigue que la posibilidad del surgimiento de la reflexión no radica en la simple estructura del para-sí qua para-sí sino en la totalidad para-sí-para-otro. El surgimiento de la reflexión cómplice, es decir, aquella que pone a la conciencia como un objeto, se encuentra condicionado por la posibilidad siempre presente de ser un objeto para un prójimo-sujeto. ¿Por qué este no sería el caso también de la reflexión pura?

A lo largo de toda su obra temprana, Sartre deja como deuda, en ocasión de cada aparición de la reflexión pura, la teorización en torno a la posibilidad de su surgimiento. Creo encontrar en el desarrollo del psicoanálisis existencial una vía teórica posible para comenzar a saldar dicha deuda. Si bien puedo estar de acuerdo en que sin la mediación de un otro la reflexión purificante no alcanza para poder revelar el proyecto fundamental del individuo, creo que dicha afirmación no se circunscribe solamente al ámbito del psicoanálisis existencial. Por el contrario, a partir de la función estratégica que opera dentro del mismo, que es proveerle al psicoanalista los datos reflexivos necesarios para poder asir la significación de un conjunto de conductas particulares, se pueden derivar algunas conclusiones relativas a su posibilidad ontológica. El movimiento reflexivo en sí no sería posible, como ya dijimos, sin la mediación de un otro. El objeto que el psicoanálisis debe sacar a la luz, el proyecto fundamental del individuo, se encuentra articulado según la estructura de la trascendenciatrascendida. Esto implica que su ser es en sí un ser-para-otro. Para que el sujeto

27 Ibid., p. 770 .

28 De acuerdo al extenso análisis del prójimo en la sección "La mirada", queda establecido que el prójimo-sujeto confiere al para-sí su objetividad constituyendo la condición necesaria de todo pensamiento que él intente formar sobre sí mismo. Esto es, la mirada del prójimo se encuentra a la base de la posibilidad del movimiento reflexivo: “... el prójimo, al fijar mis posibilidades, me revela la imposibilidad en que estoy de ser objeto excepto para otra libertad. No puedo ser objeto para mi mismo, pues soy lo que soy; abandonado a sus propios recursos, el esfuerzo reflexivo hacia el desdoblamiento termina en fracaso: siempre soy reatrapado por mí. Y cuando postulo ingenuamente que es posible que yo sea, sin darme cuenta, un ser objetivo, supongo implícitamente por eso mismo la existencia del prójimo; pues ¿cómo podría ser yo objeto sino para un sujeto? Así el prójimo es ante todo para mi el ser para el cual soy objeto, es decir, el ser por quien gano mi objetividad. Si he de concebir asi sea una sola de mis propiedades en el modo objetivo, ya está dado el prójimo" (ibid., p. 348). 
pueda acceder a su propio proyecto fundamental, el mismo tiene que serle dado desde el punto de vista del prójimo. Asi pues, se demuestra la incompatibilidad entre la existencia para-sí y la existencia objetiva. El proyecto solo puede ser vivido por el para-sí y solo puede ser conocido en tanto proyecto-para-otro. La imposibilidad del auto-análisis, esto es, de que el psicoanálisis existencial pueda ser llevado a cabo solo a partir de la reflexión autónoma, nos arroja una certeza ontológica: la imposibilidad del para-sí de coincidir consigo mismo, es decir, la irreductibilidad de su elección fundada sobre la falta de ser. El autoconocimiento auténtico es, en sí, un proyecto fallido puesto que el para-sí no puede ser a la vez sujeto de conocimiento y objeto conocido. La reflexión cómplice me ofrece un cogito sustancializado, es decir, falseado, mientras que la reflexión pura se revela como imposible de surgir sin la mediación de un otro que pueda entregarme el significado a revelar de mi proyecto originario. Esto demuestra que el secreto de mí misma no lo encontraré nunca en mí, puesto que nunca llegaré a ser un "sí mismo para mî", sino que siempre seré un "sí mismo para otro" y ajena para mí misma. Yo soy otra. La opacidad es, en definitiva, ineludible.

\section{Conclusión}

Retomando la idea que expuse previamente a través de Simone de Beauvoir, diré que el psicoanálisis existencial toma su necesidad, al igual que la moral, del fracaso que supone la existencia humana. A través de la tematización del deseo como concepto clave de acceso a la ontología sartriana, he podido confirmar dicho fracaso, el cual condena al existente humano a lidiar en su existencia con una opacidad constitutiva e insoslayable. He establecido que el reconocimiento, dentro de la ontología sartriana, no es una posibilidad actualizable. La reflexión pura, como intento de recuperación del proyecto del para-sí por sí mismo es otra expresión del fracaso inherente al existir. El psicoanálisis existencial, como método que pretende acceder a la elección fundamental, contingente y singular de cada individuo, atestigua dicha fatalidad condenando la posibilidad de conocimiento de sí mismo a la apertura ante el otro. Entiendo, a diferencia de Sartre, que la reflexión pura sí constituye el punto de llegada del psicoanálisis existencial. Solo que ella debe ser entendida como una posibilidad del para-sí-para-otro, puesto que lo que la misma nos revela es que todo proyecto individual es un proyecto para un otro. En la búsqueda de la interioridad del existente humano la reflexión pura no se equivoca: dicha interioridad no existe. Lo que la reflexión pura, en última instancia, revela al 
existente humano es su nada-de-ser. La estructura originaria del existente humano se reduce a una nada que no puede dar el salto a la existencia como ser-en-el-mundo sin el ser que le confiere el prójimo. Esta revelación abre al existente humano la posibilidad de la conversión existencial, es decir, abre la posibilidad de una existencia auténtica en comunidad y abre el espacio de creación de valores bajo las coordenadas de una ética de la responsabilidad existencialista.

\section{Bibliografia}

De Beauvoir, S., Para una moral de la ambigüedad, Buenos Aires: Schapire, 1956.

Butler, J., Sujetos del deseo. Reflexiones hegelianas en la Francia del siglo XX, Buenos Aires: Amorrortu, 2012.

De Coorebyter, V., "Les paradoxes du désir dans L'Être et le Néant" en: Barbaras, R. (comp.), Sartre: Desir et Liberté, París: PUF, 2005.

Jeanson, F., Para una moral de la ambigüedad, Buenos Aires: Siglo Veinte, 1968

Mouillie, J-M., Conscience, ego et psyché, Paris: PUF, 2000.

Sartre, J-P., "Una idea fundamental de la fenomenología de Husserl: la intencionalidad" en: Situations I, Buenos Aires: Losada, 1967.

Sartre, J-P., Cahiers pour une morale, París: Gallimard, 1983.

Sartre, J-P., El ser y la nada, Buenos Aires: Losada, 2005.

Recibido: 03/01/2016

Aceptado: 14/09/2016 